\title{
The role of the imagination in museum visits
}

\author{
Marianne Achiam
}

\begin{abstract}
The imagination plays an important role in museums, today more than ever. Visitors use their repositories of imagination or repertoires to make sense of their encounters with objects and exhibits. In this article, I argue that this initial meaning making, rather than being the end goal of museum interpretation, should be thought of as the point of departure for further, more scientific meaning making. I present a framework developed by Colette Dufresne-Tassé et al. (2006) and show how it can be used to identify the variety of visitor repertoires at work in their imagination processes. I argue that becoming familiar with commonly occurring repertoires is necessary for exhibition designers in order for museums to continue to take their interpretive responsibility seriously, and I discuss how such a familiarisation may affect museum practice. I conclude with some perspectives on the implications of the framework for museum research.
\end{abstract}

Keywords: Imagination, interpretation, repertoire, exhibition design, constructivism.

The imagination plays an all-important role in museums. In 1958, Katharine Beneker discussed the ability of exhibitions to "fire the imagination" of visitors, carrying them into new, previously unknown areas of knowledge. Today, this quality is perhaps more important than ever (Asma 2001:38ff., McLean 2007), as the traditional functions of museums are redefined and subsumed into new metafunctions (Dubuc 2011). Such meta-functions include a renewed perspective on museum education as engaging with content in a variety of tangible and intangible ways (Dubuc 2011), generating the conditions for the suspension of time and place by offering visitors new symbolic experiences beyond those constrained by buildings, ownership, or location (Beetlestone et al. 1998), and creating and reinforcing a sense of identity and culture in the face of the forces of globalisation (Knell 2011). These functions arguably entail the sparking and harnessing of the visitor's imagination, yet few studies have addressed the role of the visitor's imagination in their exhibition experiences (Bedford 2004, Dufresne-Tassé et al. 2006). Here, I present and discuss a framework for observing and describing the influence of the imagination on museum visits, and I argue for its utility in the 
design of museum experiences. Finally, I offer some perspectives on the implications of the framework. I take my point of departure in science and natural history museums, although I believe that the perspectives presented here have wider application.

Throughout this text, I view imagination as the essential capacity that enables us to form a mental representation of something (Gendler 2013). It allows us to see and think in new ways, and to create fictive situations and possibilities (Bedford 2004). Imagination is involved in the synthesis of new knowledge because it allows us to create mental constructions based on observation, existing knowledge, and what is not present (Greene 1988); it is thus central to learning (Sneath et al. 2009, Hadzigeorgiou 2015). It is distinct from memory in that imagining something does not require that something to be or to have been the case, whereas remembering something does (Gendler 2013).

\section{IMAGINATION AND MUSEUMS}

In natural history museums in the late nineteenth and early twentieth centuries, the visitors' meaning making of the objects on display was thought to be governed mainly by the authority of those objects. In other words, the authentic scientific voice of the objects and their setting-in-scene in exhibitions constituted the authority of the imaginary processes (mental images, situations, and possibilities) that occurred in the visitor's interactions with the exhibition (Evans et al. 2002, Meszaros 2006). The presumed ability of the scientific objects to speak for themselves served to maintain the museum's authority to present the "truth" (Roberts 1997:60ff.), while ignoring the perspective of the visitor (Wertsch 2002).

In the 20th century, this object-based epistemology (Conn 2010:7f.) was succeeded by a conception of meaning making as taking place in relation to the individual. In this new object-based discourse, the object's participation in the cultural or lived history of the visitor was thought to play a central role in the imaginative processes. This conception was based on a growing realisation that visitors brought their own, equally valid voices to the encounter, and that these voices were the basis of the meaning created in the visitors' experiences with the objects (Evans et al. 2002, Meszaros 2006). This perspective remains influential today among museum professionals (cf. Roberts 1997:60ff., Adams et al. 2003).

A disadvantage to shifting the interpretative authority from the museum and placing it in the hands of the visitor is that the scientific nature of the museum objects may be "relegated to a supporting part" (Evans et al. 2002:58). This is problematic, not just because it obscures the natural history or science of an object (Evans et al. 2002), but because it can be used in a wider sense to absolve the museum of interpretative responsibility (Meszaros 2006): If the museum has no control over the way visitors interpret the objects in exhibitions, surely it cannot be responsible for these interpretations? There are, however, problems with this argument. Even though most would agree with the basic notion that all knowledge construction is based on context and prior knowledge, this does not mean that cultural or scientific knowledge should be disregarded in the name of personal meaning. Nor does it mean, by extension, that any failure of the museum to communicate scientific content is justified (Meszaros 2006, Shettel 2008). Rather, it is important to acknowledge that the imaginative processing of museum visitors arises from a variety of repertoires which certainly include the visitor's existing knowledge, but also 
Fig. 1. A diorama in the Natural History Museum of Denmark. The diorama features a deciduous forest habitat with a lynx (Lynx lynx) and a wild boar (Sus scrofa). Photo: Marianne Achiam, 2013.

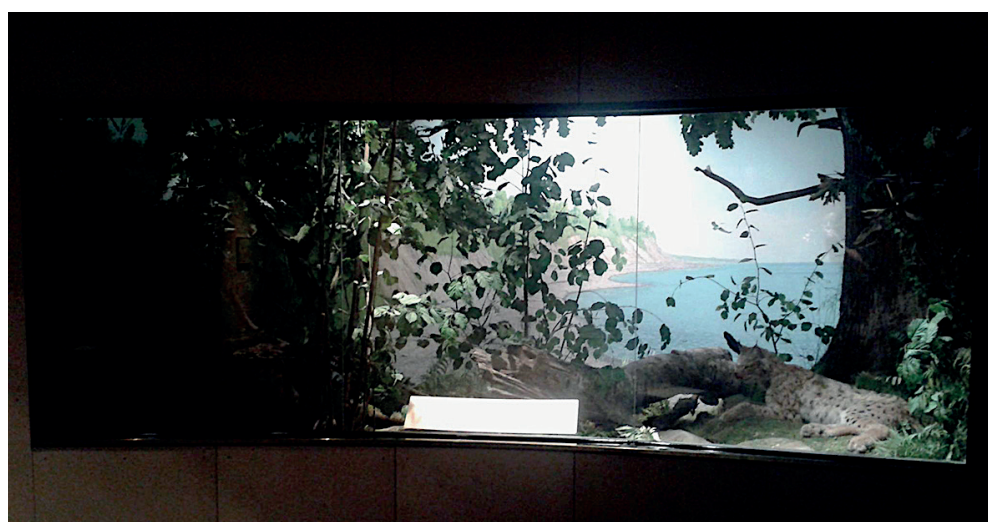

Fig. 2. The discovery room at the Natural History Museum of Denmark. The discovery room features a number af taxidermied specimens of Danish and Nordic wildlife as well as other objects (e.g. skulls, bones, furs, and preserved invertebrates in jars). Photo: Marianne Achiam, 2013.

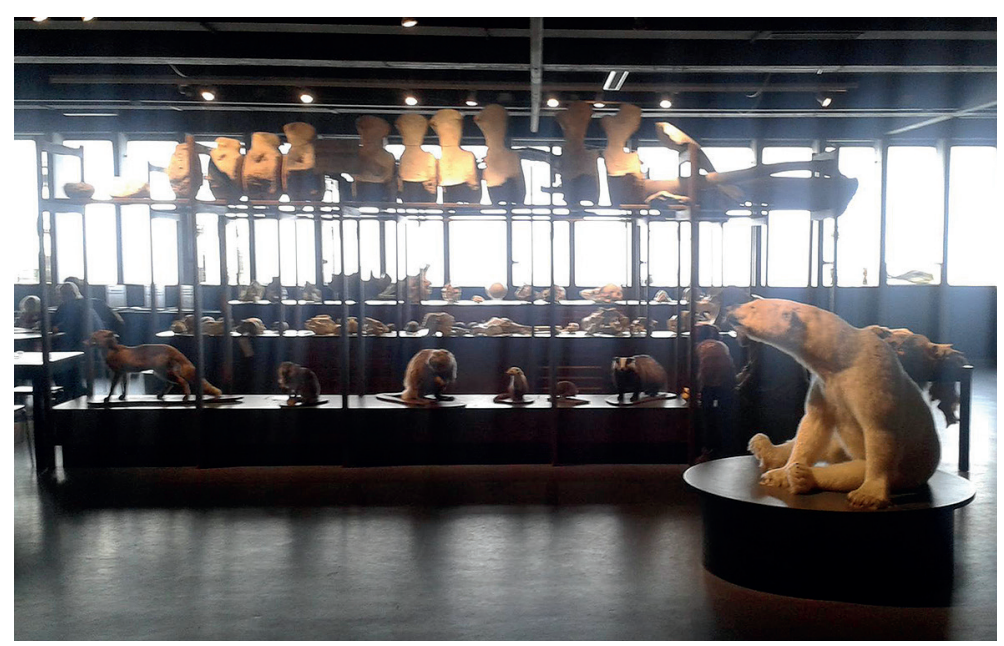

include the object's scientific nature, its specific affordances and setting-in-stage, the designer's intentions, etc. (Roberts 1997:137ff., Gurian 1999). What is lacking in a more current perspective, then, is a model that can link scientific knowledge to personal interpretation as a way of understanding how our imagination shapes our actions in designed environments in museums (Meszaros 2006).

With a point of departure in this observation, I now present an analytical framework, developed by Dufresne-Tassé et al. (2006), that describes and categorises the imaginative functioning of museum visitors. I exemplify the framework using an empirical data set, collected as part of another study (Achiam et al. 2014). Briefly, these data consist of observations and audiorecordings of visitors' think aloud verbalisations (van Someren et al. 1994) as they contemplated either dioramas (fig. 1) or animal specimens in a discovery room (fig. 2) at the Natural History Museum of Denmark. Six adults were observed 
and recorded at dioramas, and six adults were observed and recorded in the discovery room. I use these data here, specifically the verbalisations, to illustrate the utility of the analytical framework developed by DufresneTassé et al. (2006) in understanding how our imagination shapes our actions in museums and in identifying the repertoires that are involved in the process. Finally, I discuss how the framework can help museum professionals re-address their interpretative responsibilities and make visible and explicit the repertoires that shape their work.

\section{ANALYTICAL FRAMEWORK}

As outlined in the introduction, imagination is understood here as the capacity of visitors to evoke or represent something that is not with them in the exhibition, but that may be from the past, exist contemporaneously with the visit, be from the future, be potential or even virtual. In a study of 90 visitors to exhibitions at three different museums, Dufresne-Tassé et al. (2006) used the think aloud method (van Someren et al. 1994) to access visitors' mental processes. From the transcriptions of visitors' discourse, Dufresne-Tassé et al. constructed an exhaustive list of fourteen different kinds of mental operations. Of these operations, five do not require the use of the imagination, three require the use of the imagination, and six are possible both with and without the intervention of the imagination.

The first family of operations consists of exclaim, observe, identify, verify, and judge. These operations use only the cognitive or affective aspects of mental processing, and do not require visitors to use their imagination. Visitors either process information as a fact or express their reaction to what they see, as shown in the following examples:
When visitors exclaim, they express their reaction to an object with a simple expression such as "Oh" or "Wow". Their feelings are not articulated in a sentence, and the mental operation is purely affective.

When visitors observe or find, they essentially recognise familiar aspects of what they are looking at. For example, they might say: "There's a little beetle." Their mental operation is mainly cognitive.

When visitors identify an object, they assign it a name, establish its author, or establish the time of its creation. They usually do this using the label. Because the information is treated factually, their mental activity is primarily cognitive. For example, they might say: “This is a roe deer, with two lambs."

When visitors verify their own knowledge or observation, they check the accuracy of it. They take a factual approach, so their activity is usually cognitive. For example: "I guess it's nowadays, but I don't really...? (reads) Oh yeah! It's nowadays."

When visitors judge, they estimate or determine the value of what they are looking at by objective or subjective criteria. When the criterion is objective, the visitor's mental activity is usually cognitive, for example: "I can mostly hear the water instead of the animals." In contrast, when the criterion is subjective, the verdict is pronounced according to the visitors' personal taste, and their activity is mostly affective. Example: "I like the scenery of another Danish forest."

The second family of mental operations consists of associate, predict, and suggest. These operations require the use of the imagination; that is, they take place through the evocation or representation of something that is not with the visitor in the exhibition, but that exists in the past, present, or future, or even as a potential or virtual thing (Dufresne- 
Tassé et al. 2006), as shown in the following examples:

To associate means that visitors connect what is being observed with information from their experience. They say, for example: "It makes me think about the south of Denmark, Møns Klint."

When visitors predict, they anticipate something that is yet-to-be, or just a possibility or hypothesis. For example, they might say: "Probably there are quite many ants [in that forest]."

When suggesting, visitors propose something outside their immediate context or they recommend a change in what they observe. An example could be: "There's this black slug; why did they decide to show that? I mean, it could have been ants on the ground, or small snails, or mosquitoes, or..."

The third and final family of mental operations consists of justify-explain, resolve, compare, grasp, clarify, and modify. These operations are possible without the use of the imagination, as the visitor may use the exhibition for assistance. However, as the following examples will show, the imagination is frequently involved in these operations:

When visitors justify-explain, they motivate, test or prove their position, using evidence to do so. Example without imagination: "I tried to listen for the birds, but there was too much noise at that point." Faced with a diorama of prehistoric Danish woodland, and using their imagination they might say: "It's different from the scenery that you would see today and the coastline. There's much more nature... it also seems quite undisturbed."

When visitors resolve, they find the solution to a problem. They reduce or remove an obstacle to further reasoning or the conclusion. An example that does not require the use of the imagination is: "I thought it was penguins, at first. But it's another kind of bird (reading label)." An example involving the imagination is: "Is it a baby [roe deer]? No, it has to be an adult - it has horns."

When comparing, visitors establish the similarities and differences (and thus the relationship) between what they observe and something else. This "something else" may be located in the same place as they are; in this case, the activity does not require imagination. For example: "And again, in comparison with the sika next to it, how big [the wild boar] is!" If the comparison is made to something outside the visitors' vicinity, their mental activity requires the use of the imagination. For example: "The lynx looks kind of like a teddy bear."

When visitors grasp, they discover the meaning of one or more objects or the way they work, with or without the use of their imagination. Example (without imagination): "It's a pelican! Okay, interesting. I didn't know it was here [in Denmark]." Example (with imagination): "Oh, I actually thought they had larger tusks than that [about a wild boar]."

When visitors clarify, they invoke a new element, a feature that helps to deepen what they are able to say or do, with or without the help of their imagination. An example without the use of the imagination could be: "It gives me a romantic impression of life here; there are no dangerous things in it." An example which includes the use of the imagination could be: "I might miss some of the background for this; I mean, why did they end up living here, why did they die out, and how similar are they to the animals today?"

When modifying, visitors nuance or diminish either their position or their perspective. The activity can be carried out with the help of their imagination or without it. Example (without the imagination): "I don't really see 
many other animals here, but there're quite a few beech trees. It's all beech forest, actually." Example (with the imagination): "And one of the first things is that it maybe looks like a seaside that I know, except for the fact that there are quite big animals."

\section{HoW DOES IMAgINATION SHAPE ACTION IN MUSEUMS?}

Dufresne-Tassé et al. (2006) use the analytical framework presented in the preceding to show that when visitors use their imagination, they spend longer time in museum exhibitions, and have richer and more fully-developed interactions with the objects in them. According to these authors, this effect is due to an enrichment of the semantic universe created by the visitor around the object. Dufresne-Tassé et al. (2006) further observe that the imagination plays this role, sometimes through its reproductive component, sometimes through its creative component. ${ }^{1}$ The reproductive component is at play when visitors associate or use their imagination to compare, because they are linking what they observe with what they already know or have experienced (cf. Dufresne-Tassé et al. 2006). In the example of association shown above, the visitor says about a diorama "It makes me think about the south of Denmark, Møns Klint”, retrieving from their memory the characteristics of Møns Klint.

Conversely, the creative component is at play when visitors use their imagination to predict, suggest, justify-explain, resolve, grasp, clarify, or modify, because they are creating mental scenarios (cf. Dufresne-Tassé et al. 2006). In the example of suggestion shown above, the visitor says about a diorama: “There's this black slug; why did they decide to show that? I mean, it could have been ants on the ground, or small snails, or mosquitoes, or..."
In this case, the visitor is mentally producing a scenario of a different diorama, suggesting that this imaginary diorama is as valid as the observed one.

In sum, the reproductive component of the imagination mainly serves to integrate what is shown in the exhibition with the visitor's experience, while the creative component of the imagination is largely responsible for the deepening, structuring, and enriching of the universe of meaning surrounding the objects in the exhibition (cf. Dufresne-Tassé et al. 2006). The authors propose the mechanism of imaginary functioning to be the following:

Imagination promotes first a personal contribution, an initial investment through which a formal relationship is established between the object and the information held by the visitor (reproductive imagination). This establishment situates the object $[\ldots]$ and creates a first level of familiarity with it. With the aid of this familiarity, visitors can more easily carry out other types of investment, enriching, deepening, strengthening and structuring the universe of meaning they create (creative imagination) (Dufresne-Tassé et al. 2006:172, my translation).

The mechanism proposed by Dufresne-Tassé et al. (2006) is consistent with a constructivist perspective of learning: A process of construction based on a person's prior lived experiences and understandings as well as the ways in which that person actively interacts with the world around them (Hadzigeorgiou 2015). The imagination is thus a kind of meaning making "engine" because it drives the initial reproductive establishment of the relationship between the object and the visitor by synthesising a conscious conception of what is seen, and the subsequent creative mobilisation of the person's background 
beliefs, memories, and expectations in order to create what is not seen. Taken together, the notions of imagination and constructivism thus explain how museum visitors' various repertoires influence their processes of meaning making in exhibitions. In the next section, I will develop the notion of repertoire, and show how the analytical framework can help museum professionals identify the repertoires at work in the interpretative work of museum visitors.

\section{REPERTOIRES AND THEIR INFLUENCE ON THE IMAGINARY PROCESS}

Repertoires may be understood as visitors' repositories of meaning making, that is, the knowledge, experience, assumptions, and conjectures that underlie their interpretation of objects and exhibitions. Although they are involved in creating a conscious conception of sensory input, the repertoires themselves are mobilised somewhat unconsciously by visitors, which makes them difficult to observe and identify. Yet, as Meszaros (2006) states, we as museum professionals cannot ignore them because they are powerful shapers of the interpretative process.

I suggest that the analytical framework developed by Dufresne-Tassé et al. can be used as a means to identify and observe repertoires in action among museum visitors, because the framework allows us to identify mental operations that involve imaginary processing, and because at the foundation of this imaginary processing, we find repertoires. Consider the following examples: Facing a diorama featuring a forest with a roe deer, one (male) visitor says: "It's more, like, species for hunting you see." This visitor is carrying out an operation of association, using his imagination in a reproductive way to identify the deer as a common object of recreational hunting in Denmark. Clearly, he is drawing (perhaps he is a hunter himself) to make this statement. Conversely, another (female) visitor facing the same diorama states: "I get a lot of questions or stories that could have been told, but aren't part of the picture. I mean, how old do they get, what do they eat, who will eat them, and so on. Eh, there are a lot of stories, but untold." This visitor is carrying out an operation of suggestion, using her imagination in a creative way to propose potential "stories" that in her opinion ought to have been addressed by the diorama. This visitor clearly draws on a repertoire regarding her perception of the educational obligations of a natural history museum. In both cases, the visitors use their imagination to make meaning of the encounter, and in both cases, the visitors draw on their individual repertoires as well as the observable features of the diorama in this meaning making.

In sum, I suggest that the analytical framework developed by Dufresne-Tassé et al. (2006) can be used as a means to identify instances of imaginary functioning among visitors; instances that can then be interrogated to clarify the embodied repertoires. This process, I suggest, is part of the collective task of museum professionals outlined by Meszaros (2006): Becoming familiar with the many kinds of meaning making repertoires so we can attend to their power over us. In the following, I contextualise these arguments and discuss their implications for museum practice at the levels of visitor meaning making, exhibit design, and the reflective practices of museum staff members.

\section{Discussion}

I have argued for a renewed focus on the dissemination responsibilities of natural 
science museums. Although to many readers it may seem self-evident that museums should take responsibility for the scientific meaning making their exhibitions engender, past decades have seen a shift, within both museum research and practice, away from the intellectual interaction between the visitor and the exhibit (Meszaros 2006, Shettel 2008). Indeed, one of the most influential (cf. Phipps 2010) conceptual frameworks in museum research, the Contextual Model of Learning (Falk \& Dierking 2000, 2013), describes the museum experience without reference to the content of what is exhibited or the imaginative trajectories made possible by that content. Although it was never the intention of Falk and Dierking (nor of constructivism) to celebrate personal meaning making to the exclusion of scientific or cultural knowledge, the framing of the museum experience as a strongly personalised event may inadvertently have contributed to the exile of cultural or scientific knowledge from the collective consciousness of museum researchers and practitioners. This is what Cheryl Meszaros refers to as

the highly selective uptake of constructivist learning principles that $[\ldots]$ prioritizes personal meaning-making as the end product of the museum encounter rather than the beginning of interpretation (Meszaros 2006:13).

It is against this backdrop that my proposal should be read.

What would it mean for museums to fully take on the task of interpretative responsibility? First of all, it would mean that rather than accepting whatever initial meaning a museum visitor makes of an encounter with an object or exhibit, the museum should view this meaning as the point of departure for further, scientific meaning making. By identifying the kinds of repertoires commonly employed by visitors, museum professionals would become better able to predict and accommodate visitors' various points of departure and thus to plan for their further experiences, helping them make scientific meaning of the content matter (cf. Hein 2006).

Second, there is evidence to suggest that exhibit genre acts as a significant prompt of visitor response (Macdonald 2007, Pedretti 2012, Achiam et al. 2014). For example, the diorama is an exhibit genre intended to illustrate the natural interactions between the animals, plants, geography, and climate of a given biome (Fortin-Debart 2003, Marandino et al. 2015) and indeed, it seems that visitors in many cases are prompted by dioramas to act as naturalists, observing the behaviours and relationships on display and drawing on their ecology repertoire to interpret what they see (Ash 2004, Reiss \& Tunnicliffe 2011, Piqueras et al. 2012). For example, Piqueras et al. (2012) report how a diorama showing scavengers at a deer carcass embodies an explicit curatorial intent to challenge the curiosity and imagination of the visitors by including "clues" to the main scene. Accordingly, the designers have placed yellow spots and footprints on the diorama's artificial snow; these are signs of a fox that has previously visited the carcass and taken away its head (a common behaviour among foxes). In their study of visitors' meaning making at this diorama, the authors show how these clues and details indeed do trigger visitors to conjecture about which animal killed the deer and took its head, using and building upon their existing ecology repertoire. I suggest that understanding the relationship between an exhibit genre and the visitor repertoires it tends to mobilise is an important step towards improved museum interpretation, because it allows exhibition designers to better take 
advantage of the "distinct ways of mediation of the genre in question" (Achiam et al. 2014:478).

Finally, I observe that although the focus here has been on the repertoires of museum visitors, it is easy to imagine how the repertoires of exhibition designers can be powerful co-authors of how and why an exhibit or exhibition takes a given shape. Lindauer (2005) showed how exhibition designers have rather tacit ways of approaching exhibition design; ways that are not always consistently applied across the design team or even by the same individual. To the extent that we can think of these design approaches as being governed by the repertoires available to the designers, we can see how repertoires indeed do influence the design process. Acknowledging that museum professionals make assumptions about science content and science education when they produce educational environments and activities, even if these assumptions are tacit or inconsistent with one another (cf. Lindauer 2005, Mortensen 2010), is an important step towards understanding what kinds of repertoires underlie these assumptions and deciding whether they contribute to producing the desired characteristics in the final product. Ultimately, this will lead to more well-reflected design practices.

\section{CONCLUSION AND PERSPECTIVES FOR RESEARCH}

In conclusion, I find that the framework of imaginary functioning (Dufresne-Tassé et al. 2006) combined with the notion of repertoire (Meszaros 2006) offers a tool to help identify and understand the imaginary processes of visitors in their interpretive work, and ultimately, to contribute to a better alignment between this interpretive work and the goals and objectives of the museum. Present-day museums rely on mobilising the imaginary 97 processes of their visitors to fulfil their new institutional meta-functions and must accordingly renew their efforts to address their interpretive responsibility; the perspectives presented here offer one way of doing so.

From a research point of view, I note that although the notion of repertoire originated in an art museum context (cf. Knutson \& Crowley 2006), it has similarities to constructs from other research domains, no doubt due to shared constructivist origins. For example, from a science education research context, Stocklmayer and Gilbert's (2002) notion of "remindings" as the ideas, objects, events, or processes that shape a visitor's exhibit interaction seems to have similar implications. And from a tourism research perspective, Voase (2002:391) observes that when visitors encounter a museum attraction, the meaning they make is shaped as much by their own memories, interests and concerns as by the encounter. It seems, then, that the constructivist notion that visitors make their own meanings in museums is broadly accepted in the research community (even if it is sometimes selectively applied). This prompts the final question: What is our role as researchers in furthering an agenda of re-addressing "interpretative responsibility" in museums?

As researchers, our role is probably not to be the agents of change in museums. Our strength lies in being able to step outside the educational system under investigation, and we are thus not obliged to take for granted the existing organisation of a scientific subject or theme as it is represented in an exhibition, as if it were the only one possible. This position gives us a unique opportunity to help identify and challenge occurrences of unspoken, unseen repertoires from which acts of interpretation arise, whether they originate among museum 
staff and manifest themselves in exhibition design, or among visitors, where they shape the ways in which meaning making can take place. But we can only assist and inform the (r)evolution of museums; the true agents of change must be the museum professionals (cf. Heimlich, 2006) who have the power to radically re-think their practices.

\section{Notes}

1. Dufresne-Tassé et al. (2006) draw on Kant when they discuss the reproductive and creative components of the imagination. While their interpretation of Kant does not, strictly speaking, align with my understanding, I retain their Kant-inspired idea of distinguishing between the reproductive and creative components of imagination due to its practical applicability.

\section{LITERATURE}

Achiam, Marianne, Michael May \& Martha Marandino 2014. "Affordances and distributed cognition in museum exhibitions." Museum Management and Curatorship 29:5, 461-481.

Adams, Marianna, John H. Falk \& Lynn D. Dierking 2003. "Things change." In Maria Xanthoudaki, Les Tickle, Veronica Sekules (eds.). Researching Visual Arts Education in Museums and Galleries. Dordrecht: Springer, 15-32.

Ash, Doris 2004. "How families use questions at dioramas. Ideas for exhibit design." Curator: The Museum Journal 47:1, 84-100.

Asma, Stephen 2001. Stuffed Animals and Pickled Heads. The Culture and Evolution of Natural History Museums. Oxford: Oxford University Press.

Bedford, Leslie 2004. "Working in the subjunctive mood. Imagination and museums." Curator: The Museum Journal 47:1, 5-11.

Beetlestone, John, Colin H. Johnson, Melanie Quin
\& Harry White 1998. “The science center movement. Contexts, practice, next challenges." Public Understanding of Science 7, 5-26.

Beneker, Katharine 1958. "Exhibits. Firing platforms for the imagination." Curator: The Museum Journal 1:4, 76-81.

Conn, Steven 2010. Do Museums Still Need Objects? Philadelphia: University of Pennsylvania Press.

Dubuc, Élise 2011. "Museum and university mutations. The relationship between museum practices and museum studies in the era of interdisciplinarity, professionalisation, globalisation and new technologies." Museum Management and Curatorship 26:5, 497-508.

Dufresne-Tassé, Colette et al. 2006. "L'imagination comme force dynamisante du traitement des objets muséaux par des visiteurs occasionnels." In Colette Dufresne-Tassé (ed.). Families, Schoolchildren and Seniors at the Museum. Research and Trends. Québec: Éditions MultiMondes, 160-176.

Evans, Margaret et al. 2002. "The authentic object? A child's-eye view." In Scott Paris (ed.). Perspectives on Object-centered Learning in Museums.

Mahwah: Lawrence Erlbaum Associates, 55-77.

Falk, John H. \& Lynn D. Dierking 2000. Learning from Museums. Visitor Experiences and the Making of Meaning. Walnut Creek: Altamira Press.

Falk, John H. \& Lynn D. Dierking 2013. The Museum Experience Revisited. Walnut Creek: Left Coast Press.

Fortin-Debart, Cécile 2003. "Le Musée de Sciences Naturelles, un partenaire de l'école pour une education relative a l'environnement: du message scientifique au débat de société." VertigO - la revue électronique en sciences de l'environnement 4:2. http://vertigo.revues.org/4494 (accessed 7 August 2013)

Gendler, Tamar 2013. “Imagination.” In Edward Zalta (ed.). The Stanford Encyclopedia of Philosophy. http://plato.stanford.edu/archives/fall2013/entries/ imagination/ (accessed 10 December 2015) 
Greene, Maxine 1988. "What happened to imagination.” In Kieran Egan \& Dan Nadaner (eds.). Imagination and Education. New York: Teachers College Press, 45-56.

Gurian, Elaine 1999. "What is the object of this exercise? A meandering exploration of the many meanings of objects in museums." Daedalus 128:3, 163-183.

Hadzigeorgiou, Yannis 2015. "Imagination and learning science." In Richard Gunstone (ed.). Encyclopedia of Science Education. Dordrecht: Springer, 480-483.

Heimlich, Joe 2006. “Three responses to Cheryl Meszaros' evil 'whatever' interpretation: Facing my ghosts." Visitor Studies Today 9:3, 17-19.

Hein, George 2006. “Three responses to Cheryl Meszaros' evil 'whatever' interpretation: Constructivism and interpretive responsibility." Visitor Studies Today 9:3, 19-20.

Knell, Simon 2011. "National museums and the national imagination." In Simon Knell et al. (eds.). National Museums. New Studies from Around the World. Oxon: Routledge, 3-28.

Knutson, Karen \& Kevin Crowley 2006. “Three responses to Cheryl Meszaros' evil 'whatever' interpretation: Bridging the gap between museums and visitors." Visitor Studies Today 9:3, 16-17.

Lindauer, Margaret 2005. "From salad bars to vivid stories. Four game plans for developing 'educationally successful' exhibitions.' Museum Management and Curatorship 20:1, 41-55.

Macdonald, Sharon 2007. "Interconnecting. Museum visiting and exhibition design." CoDesign 3:S1, 149-162.

Marandino, Martha et al. 2015. "The diorama as a means for biodiversity education." In Sue Tunnicliffe \& Annette Scheersoi (eds.). Natural History Dioramas. History, Construction and Educational Role. Dordrecht: Springer, 251-266.

McLean, Kathleen 2007. "Do museum exhibitions have a future?" Curator: The Museum Journal 50:1, 109-121.
Meszaros, Cheryl 2006. "Now THAT is evidence.

Tracking down the evil 'whatever' interpretation." Visitor Studies Today 9:3, 10-15.

Mortensen, Marianne 2010. "Museographic transposition. The development of a museum exhibit on animal adaptations to darkness." Éducation \& Didactique 4:1, 119-137.

Pedretti, Erminia 2012. "The medium is the message." In Eva Davidsson \& Anders Jakobsson (eds.). Understanding Interactions at Science Centers and Museums. Rotterdam: Sense Publishers, 45-61.

Phipps, Molly 2010. "Research trends and findings from a decade (1997-2007) of research on informal science education and free-choice science learning." Visitor Studies 13:1, 3-22.

Piqueras, Jesús, Per-Olof Wickman \& Karim M. Hamza 2012. "Student teachers' moment-tomoment reasoning and the development of discursive themes - an analysis of practical epistemologies in a natural history museum exhibit." In Eva Davidsson \& Anders Jakobsson (eds.). Understanding Interactions at Science Centers and Museums. Approaching Sociocultural Perspectives. Rotterdam: SensePublishers, 79-96.

Reiss, Michael \& Sue Tunnicliffe 2011. “Dioramas as depictions of reality and opportunities for learning in biology." Curator: The Museum Journal 54:4, 447-459.

Roberts, Lisa 1997. From Knowledge to Narrative. Educators and the Changing Museum. Washington, DC: Smithsonian Institution Press.

Shettel, Harris 2008. "No visitor left behind." Curator: The Museum Journal 51:4, 367-375.

Sneath, David, Martin Holbraad \& Morten Axel Pedersen 2009. “Technologies of the imagination. An introduction." Ethnos 74:1, 5-30.

Stocklmayer, Susan \& John Gilbert 2002. "New experiences and old knowledge. Towards a model for the personal awareness of science and technology." International Journal of Science Education 24:8, 835-858.

van Someren, Marten, Yvonne F. Barnard \& Jacobijn 
Marianne ACHIAM

A.C. Sandberg 1994. The Think Aloud Method. A Practical Guide to Modelling Cognitive Processes. London: Academic Press.

Voase, Richard 2002. "Rediscovering the imagination. Investigating active and passive visitor experience in the 21st century." International Journal of Tourism Research 4:5, 391-399.

Wertsch, James 2002. "Epistemological issues about objects." In Scott Paris (ed.). Perspectives on Object-Centered Learning in Museums. Mahwah: Lawrence Erlbaum Associates, 113-118.
Marianne Achiam, Ph.D. achiam@ind.ku.dk

University of Copenhagen Department of Science Education Øster Voldgade 3 DK-1350 Copenhagen, Denmark http://www.ind.ku.dk 